\title{
Technology Foresight and Sustainable Innovation Development in the Complex Dynamical Systems View
}

\author{
Klaus Mainzer \\ Professor $^{\mathrm{a}, \mathrm{b}}$; and President ${ }^{\mathrm{c}}$, mainzer@tum.de \\ a Technical University of Munich, Arcisstraße 21, 80333 München, Germany \\ ${ }^{\mathrm{b}}$ Carl Friedrich von Weizsäcker Center, Eberhard Karls University Tübingen, \\ Geschwister-Scholl-Platz, 72074 Tübingen, Germany \\ ${ }^{\mathrm{c}}$ European Academy of Sciences and Arts, Sankt-Peter-Bezirk 10, 5020 Salzburg, Austria
}

\begin{abstract}
I

nformation and communication technologies (ICT), which are transforming most areas, develop non-linearly.

Failure to take into account the nonlinear principles of complex dynamic systems hinders the development of balanced innovation strategies. Companies and governments lose the ability to effectively respond to "grand challenges". The linear approach does not allow for covering a wide range of critical areas simultaneously in the scope of Foresight projects as it prevents one from applying an interdisciplinary approach to developing innovation strategies, correcting risk assessments, and making informed decisions.

This paper proposes a solution: management based on "cyber-physical systems" (CPS) built on dynamic complexity and nonlinearity principles. Such systems not only integrate computing and physical action but are embedded in the

everyday environment. They are more than the sum of multiple intelligent computing devices. CPS transform into collective social systems, integrate information, energy, and material flows, and adapt to physical processes.

Cyber-physical systems can offer a sustainable information infrastructure which serves as a prerequisite for building up the innovative potential of a company, region, or country. They make it possible to analyze all stages of an innovation project from the technical and organizational points of view simultaneously, to cover all possible social consequences and challenges, and identify unexpected promising developments. CPS have a decentralized structure which allows one to solve complex problems and manage large and complex structures in real time, such as an energy grid, transport, smart city, healthcare, and so on.
\end{abstract}

Keywords: socio-technical systems; innovation strategies; foresight; complex dynamic systems; inter-disciplinary approach; management of complex structures; cyberphysical systems
Citation: Mainzer K. (2020) Technology Foresight and Sustainable Innovation Development in the Complex Dynamical Systems View. Foresight and STI Governance, vol. 14, no 4, pp. 10-19. DOI: 10.17323/25002597.2020.4.10.19 
I $\mathrm{n}$ the past, corporate strategies were often based on the assumption that digital technologies develop exponentially. This applies to growing computing power and data storage capacity, reduced size and cost of devices, and increased efficiency, among other things. Accordingly, it was believed that economic success would only be a matter of flexibly adapting to this context.

However, all of history shows that technological development has never been subject to rigid laws. Emerging innovation impulses often "pushed" this development in unforeseen directions. In the middle of the last century, computer pioneers relied on a few powerful mainframes. Then young entrepreneurs came up with small start-up companies producing many small personal computers (PCs) which have quickly spread all over the world. ${ }^{1}$ Even the internet in its current version as the basis for worldwide communication was initially not on the screen when military communication networks were set up to secure command structures in the event of a nuclear strike. The exponential success of smartphones and their manufacturers was not envisioned in the long term either. Likewise, nobody knows today which developmental improvements can be expected in the coming decades and which trend reversals they could initiate. In a way science and technology development is similar to biological evolution [Nelson, Winter, 1982; Nelson, 2018]. In such a system, innovations play the role of mutations, markets make selections and social frameworks affect the development of trends - just like ecological conditions determine evolution. However, the algorithms of evolution remained "blind" for millions of years, while humans are (still) conscious of the course of technological development and can control and influence it, at least for short periods of time. In turn, visions of the future determine people's goals and aspirations and, through the awareness of cause-and-effect relationships, influence future development; this is called the "normative force of the factual" [Bezemek, 2019]. In other words, visions of technological development prospects can create ardent supporters of the corresponding trends. If these supporters happen to be executives at leading companies or prominent researchers, the relevant scenario will most likely be implemented.

Thus, a prediction becomes reality ("self-fulfilling prophecy") [King, 1973; Pop, 2015; Biggs, 2017]. The history of evolution shows that despite the fundamental "deterministic" laws, various possibilities exist for the implementation of various scenarios, but only a few become reality. That is, the laws of nature themselves make the future "open", so we should speak not about "a future" but of multiple "futures" [Glenn, Gordon, 2009; Ringland, 2010; Godet, Roubelat, 1996; van der Heijden, 1996]. Changes in economic, environmental, and social conditions and shifts in the technological landscape itself affect the vector of its further development. Therefore, an approach known as technological design ${ }^{2}$ should be applied to developing new products and processes.

\section{Applying Scenario and Delphi Procedures to Develop Corporate Strategies}

While big data-based techniques analyze the future with powerful algorithms and quantitative methods, scenarios and Delphi procedures allow one to gain qualitative insights into the future. Unlike forecasts, they are not intended to accurately "calculate" the future, but to provide an idea of how events might develop. Scenarios are based on a deep and comprehensive understanding of events and rely on the knowledge, experience, and intuition of experts who assess possible scenarios for the future [Häder, 2002]. These approaches do not aim to forecast, but to assess potential futures. Scenarios describe the future context in the form of hypotheses whose analysis allows one to identify causal, logical connections and possible consequences, and to assess alternative future scenarios as more or less desirable. The starting point is analyzing the present and the past on the basis of empirical evidence. Then a baseline (trend) scenario is built, which is extrapolated into the future under the assumption of certain constraints remaining in place. As certain other conditions are assumed to change, alternative scenarios are proposed, which deviate further and further from the trend scenario as the distance from the present increases. A kind of funnel emerges, which, starting in the present, opens ever further around the time axis of the trend scenario. Extreme positive and negative scenarios are located at the margins.

A good example of this is energy industry development scenarios. Most of them are based on the assumption that the demand for traditional energy resources will remain in place in the coming decades, so development prospects for alternative energy sources are assessed. Accordingly, scenarios describe various futures depending on the political decisions made.

Another tool widely used for the expert assessment of possible developments is the Delphi method

\footnotetext{
${ }^{1}$ See, e.g.://newsroom.intel.com/editorials/pc-evolution-from-mainframe-to-perceptual-computing/\#gs.gqgpqe, accessed on: 26.09 .2020$.

2 Technological design is an approach applied to develop most of the latest technologies. Like research, it is based on fact and evidence and implies taking a particular sequence of steps to solve problems or answer questions. Technological design includes the following stages: identifying a problem, investigating it, developing possible solutions, choosing the best one, creating a model, testing it, improving and retesting it if necessary, and making a final decision. For more see, e.g. [Berg, 1998].
} 
[Glenn, Gordon, 2009; Häder, 2002]. Unlike scenarios, this involves collecting and iteratively processing the opinions of a large number of experts, which ultimately leads to building a certain shared vison of the future. Delphi is used by ministries and research organizations to support decision-making about investments in promising innovations. Experts' knowledge, experience, ideas, and visions are reviewed through a series of iterations. In the end, a single agreed upon vision of the future or a set of realistic, alternative options is formed. The customer receives recommendations on project implementation strategy. The effectiveness of this method depends upon the experts' qualifications and their abilities in interdisciplinary cooperation. As long as trends in a specific discipline are evaluated, problems usually do not arise. However, they do appear when a comprehensive, interdisciplinary assessment of a complex socio-technical system such as a "smart city" is in order.

When it comes to building infrastructure facilities such as power plants, airports, or transport interchanges, security systems are primarily based on the opinions of engineers. However, to assess how the new facilities will affect the quality of life, how convenient they would be to use, sociological surveys will be needed. No less important is a direct dialogue with the public, to involve it in decisionmaking. A complex assessment and communication process emerges during which not only interdisciplinary knowledge, but also people's opinions and attitudes must be taken into account. This makes assessing risks and making informed decisions even more complicated.

\section{From Socio-Technical Systems to Intelligent Infrastructures}

Digitization and artificial intelligence (AI) technologies are radically transforming socio-technical systems [Mainzer, 2019]. Classic computer systems clearly separated the physical and virtual worlds. Mechatronic control systems (such as those installed in modern cars and airplanes, with numerous sensors and actuators) [Isermann, 2009] no longer fit into this paradigm. They scan the environment, process the collected data and themselves can influence the physical environment in a coordinated way [Hawkins, Abdelzaher, 2005]. The next step in the development of mechatronic systems is the introduction of "cyber-physical systems" (CPS), which not only integrate computer control with physical action, but are embedded into the everyday environment (e.g., integrated intelligent power supply systems) [Lee, Seshia, 2016; NSF, 2008; Giaimo et al., 2020]. CPS consist of numerous networked components that independently coordinate their operations to accomplish a common objective. Thanks to networked embedding in system environments, CPS go beyond isolated mechatronic systems because they are more than the sum of multiple intelligent computing devices [Rajkumar et al., 2010].

Individual subsystems' intelligent functions are extended over the entire system. Like the internet, CPS transform into collective social systems which, in addition to information flows, also integrate energy, material, and metabolic flows (such as mechatronic systems and organisms). Historically, CPS research originated in the field of "embedded systems" and mechatronics [Wayne, 2008]. The integration of information and communication systems into everyday life has led to the emergence of new performance requirements such as fault tolerance, reliability, zero disruption, and secure access, with simultaneous implementation in real time. However, problem areas have become increasingly obvious over the course of embedding appropriate management and control processes, which affect the economic and environmental efficiency of the applied solutions. Examples include automatic traffic control systems designed to prevent congestion and shorten individual travel times [Wedde et al., 2007]. Powering electric vehicles with alternative energy sources, in particular solar panels or wind turbines, turned out to be no less difficult. This also applies to other renewable energy sources that are perceived as a sufficiently reliable and cost-effective alternative or backup energy source for power grids. These increasingly complex applications require highly adaptable control systems, flexible system architecture, the ability to quickly deal with failures, and scope for expansion and enlargement. Attempts to manage such systems centrally turned out to be a major obstacle to meeting these requirements. The need to process colossal amounts of data increases the required time and makes it difficult to take the necessary steps quickly. For example, large transport systems are highly dynamic. Therefore, even if traffic jam reports are transmitted to the traffic control center every two minutes, they cannot be analyzed and acted upon quickly enough to adapt to the actual traffic situation. As a result, specific vehicles' navigation systems calculate individual alternative routes. However, if all devices in the system used the same statistical algorithm, then in an effort to avoid traffic jams, all transport is directed along the same route, which only increases the chaos. Therefore, CPS aim to adapt control processes and information flows to the physical processes of the relevant applications [European Commission 2006] - just like the feats evolution has achieved over the course of organisms' and populations' development.

Top-down software structures superimposed on physical processes "from above" are not the solution. Distributed control, bottom-up management 
of layered control structures, highly autonomous software processes, and distributed learning strategies for agents are the benchmarks. One example is smart grids which, in addition to electricity, transmit data to ensure their normal functioning. Global and transnational network structures are emerging (similar to the internet), which include both combined heat and power plants for generating electricity from fossil fuel, and installations based on renewable sources (photovoltaic converters, wind farms) and biogas power generators.

Households also can generate energy using photovoltaic systems, biogas plants, or fuel cells, for themselves and other users [Al Dakheel et al., 2020]. This implements the "local activity" principle: the input from a domestic energy source is fed into the grid and contributes to global distribution patterns. Thus, smart grids with integrated communication systems provide a dynamically regulated power supply [Wedde, Lehnhoff, 2007]. This is an example of large and complex structures operating in real time according to the cyber-physical systems' principles. Large power plants create a reserve supply of energy to deal with peak loads or voltage drops. The task of intelligent systems in this case is to flexibly redistribute accumulated energy reserves according to users' needs. The main problem with switching to renewable energy sources is the large number of limitations in terms of functionality, safety, reliability, timely delivery, fault tolerance, and adaptability. Cyber-physical systems with their decentralized bottom-up structure seem to be a solution, ensuring the functioning of our increasingly complex communication and supply systems. Central to this is the organization of data streams that control the energy supply like the nervous system of an organism.

Complex networks are an example of dynamical systems which can be modeled in the scope of the mathematical theory of complex systems and synergies [Mainzer, 2007]. From cellular automata ${ }^{3}$ to neural networks and the internet, network structures are created in nature and in the technological domain, in which complex systems' elements interact according to local rules. Locally active elements (neurons, transistors, and nodes) form complex combinations and structures that affect the overall performance of the entire system. The same applies to the vital activities of organisms, cognitive functions of the brain, swarm intelligence [Lozito, Salvini, 2020], and the organization of technical infrastructures such as energy systems. Knowledge of network mathematics is required to calculate these systems' characteristics and relevant indicators. The first practical challenge in networking is the digitization of existing infrastructure, most of which was created separately with no coordination for their interaction. This is true for transport, energy, healthcare, administration, and education. The creation of the "Internet of Things" has led to the emergence of overlapping functional areas such as the smart home, smart production, smart city, and smart region. The intelligent networking of previously separate domains opens up new opportunities for greater efficiency and further development. However, new challenges also emerge: integrating technical, economic, legal, regulatory, political, and social aspects. Intelligent networks and services are created by linking classic infrastructures and augmenting them with artificial intelligence (autonomously operating, self-managing functions and components). Infrastructures' and networks' "intelligence" arises both "vertically" within a domain (e.g. healthcare or transport) and "horizontally" across domains [Sa, Corke, 2014; Alegre et al., 2014; Bassett et al., 2017].

\section{Corporate Strategies in the Context of Industry 4.0}

The ubiquitous penetration of internet technologies into industrial production marked the beginning of the next stage of industrialization, Industry 4.0 [Schwab, 2016]. The first industrial revolution (Industry 1.0) is associated with the invention of the steam engine. The second wave (Industry 2.0) came with the introduction of the assembly line-based production system first tested at Henry Ford's plant, essentially algorithmic in nature: the product is created step by step in line with a rigid program separating work operations. In Industry 3.0, industrial robots get involved in the production process; however, they remain stationary and always execute the same program to perform a specific task [Tantawi et al., 2019]. In Industry 4.0, the manufacturing process is governed by the Internet of Things. The equipment, transport, and personnel "communicate" with each other in a flexible production process. Big data plays a key role here, which comprises not just companies' structured business indicators but also unstructured social networks data, sensor signals, audio, and video [Dean, 2014]. In Industry 4.0, products can be manufactured individually by a specified time, taking into account every nuance of the customer's preferences. Technology, production, and the market are integrated into a socio-technical system that flexibly self-organizes and automatically adapts to changing conditions. This is a vision of a cyber-physical system for industry [Acatech, 2011, 2012]. To set it up, data from machines and sensors must be traced, transmitted, analyzed, and integrated with text documents.

${ }^{3}$ A cellular automate is a discrete model used in a number of natural science disciplines including micromechanics. It is mainly applied to study the algorithmic solvability of certain problems and determine the starting points for building procedures to solve them. For more see, e.g. [Schiff, 2007]. 
Appropriate big data technologies aim to accelerate business processes and are expected to support rapid and efficient decision-making.

In the Industry 4.0 context, computer numerical control (CNC) machine tools are networked, communicate with parts and components via RFID chips, and take measurements on their own. Delivery systems are also automated. Thus, it becomes possible to use social cognition over the course of the human-machine interaction. Employees' workload is reduced, while productivity is increased. However, qualified personnel are required for adjusting and setting up the machines. In addition to customized flexible manufacturing, Industry 4.0 expands the possibilities for decentralized personalized energy supply. Across the spectrum, from industry to personalized medicine, there is a departure from mass standardized production a la Henry Ford. In recent decades, computing power doubled approximately every 18 months, while devices were getting increasingly smaller and more affordable. This trend is also observed for the number of sensors, the amount of data, and so on. Companies face the need to adapt their corporate structures to enable flexible, intelligent problem solving. Due to the application of ICT, the traditional material (physical) production is gradually turning into a "virtual" process, controlled by applications and software modules. Unmanned technology is penetrating increasingly more areas. For example, Google, a prime example of an exponentially growing IT company, is already building autonomous electric vehicles. Major prospects are associated with the large-scale application of $3 \mathrm{D}$ printing technology in the automotive industry; the latter could be radically transformed if vehicle parts and components are 3D-printed at a low cost. A lot will depend upon what kind of data is entered into these $3 \mathrm{D}$ printers, and by whom. IT companies are changing almost every business, but they also need to adapt. A good example is Microsoft which continues to produce Industry 2.0-style software for mass consumers with "standard" needs. Energy companies are increasingly focusing on the decentralized market and relying on individual advice to find the right solutions. New business models are emerging, such as "buy and build" [Francis et al., 2013; Bansraj et al., 2018]. A focus on deeper customization and personalization of needs is a hallmark of smart companies, for whom building consumer confidence is paramount. However, there is also some scepticism about "cloud technologies". Successful medium-sized companies will not be storing their data in the cloud, both because of fears of industrial espionage and the significant costs with uncertain payoff prospects.

Outdated security technologies are a weak point of Industry 4.0. Therefore, ensuring proper security will also require new solutions in order to safely store information and prevent unauthorized access to it. The data security issue also has a human dimension. Process automation is only possible be- cause numerous sensors, cameras, photoelectric sensors, and other devices constantly record a huge amount of data. So, the question arises about who should have access to it, where and for how long it should be stored, and about its potential users. There is also an extensive debate under way about the impact of automation upon labor markets and the social implications of the proliferation of artificial intelligence. Smart factories are built to increase production efficiency and eliminate routine and mechanical operations, manual and intellectual alike. This approach is not at all new; it has accompanied industrialization since the 19th century. Despite the elimination of some jobs, it also generates demand for new ones. Customer service is of particular importance here, as communicating with clients and developing business models requires not only a wide range of business and management knowledge and skills, but also flexibility, experience in dealing with people, and knowledge of psychology. Most of the new professions are associated with mechatronics and robotics. Therefore AI-based automation does not create unemployment but helps cut production costs and thus contributes to the growth of the labor market for a wide range of skilled workers. This will allow countries with an educated and highly skilled workforce to "repatriate" production from low-wage countries. In the already highly automated Germany, the unemployment rate is significantly lower than in other European countries, where unemployment is associated with a lack of labor market reforms.

The popular assumption that in the future only highly qualified engineers with higher education will be in demand while everything else will be done by machines is groundless. Innovation will remain relevant in all areas. In engine development and production line design, engineers will need to master mechanical engineering-, electronics-, and information technology-related skills - disciplines which used to be outside their domain. Engineers will need to work on specialized teams to meet the complex challenges of Industry 4.0, so interdisciplinary collaboration skills are becoming a requirement. "Lathe operators" will remain in metalworking, but they will be managing networked CNC lathes. Accordingly, the requirements for their qualifications will change. In many areas the innovation cycle is already faster than training cycle. Therefore, the development of training programs requires particular attention, given the rapid obsolescence of software and many production tools. In the future, lifelong learning will become the norm, especially mastering new processes.

\section{Criteria for a Responsible Approach to Building Intelligent Infrastructure}

The integration of computer networks into social infrastructure, taking into account social, econom- 
ic, and environmental factors is believed to be the most important condition for transforming sociotechnical systems into platforms for the provision of various services.

These systems must be networked (e.g., via the internet), robust to disturbances, and be able to adapt and flexibly respond to changes [Jones et al., 2013; Behymer, Flach, 2016; van de Poel, 2020]. They are already being implemented in offices, households, social institutions, and transport. As complex systems, intelligent infrastructures has to integrate various technological domains [Geisberger, Broy, 2012]. They must be controlled by common software which provides middleware tools for translating user instructions into machine language (e.g., smart homes, smart factories, smart hospitals or transportation systems). Intelligent infrastructure such as a city or an airport is considered a virtual machine. ${ }^{4}$ The integrated client interface provides transparent and user-friendly interaction with the system. At a deeper level are certain domainspecific architectures such as the transport system, healthcare system, and industrial enterprises, where the work is actually done and services are provided to users. This model can be applied in a city management system covering transportation, healthcare, and industrial facilities including municipal power supply, garbage incinerators, and others. Common software ensures interoperability with specific user applications. The technical design of information infrastructure requires interdisciplinary cooperation between specialists in engineering and natural sciences and humanities (economics, physics, mechanical engineering, electrical engineering, computer science, cognitive psychology, communication sciences, sociology, and philosophy). This cooperation should be based on unique models integrating cognitive, knowledge, and mental aspects as well as approaches to problem solving based on advances in sociology and the philosophy of technology. Integrated design and the creation of information infrastructure will only work effectively if various aspects of the human factor are taken into account. Integrated hybrid systems, distributed digital control architectures, human-machine interaction mechanisms, integrated action models, and socio-technical networks should be developed using human-centered engineering methods [Boy, 2017].

This approach involves the step-by-step development of reference architectures, domain models, and application platforms for specific disciplines. They serve as prerequisites for conscious situational and contextual perception, process interpretation and integration, and, as a consequence, the efficient application and control of the relevant systems. The role of the human factor in information infrastructure needs to be studied on an interdisciplinary basis. A wide range of issues must be addressed, such as ergonomics, the integration of adaptive structures into the workflow, cause-andeffect relationships, and changes in social behavior due to the use of such systems. Despite the fact that these systems are multifunctional and provide a variety of services, interaction with them should be simple, reliable, and intuitive. Complex networks with an ever-increasing number of participants are becoming more difficult to control. Accordingly, the need to ensure these systems' reliability, safety, privacy and, as a consequence, users' trust, increases. The benchmarks here can be as follows:

- energy efficiency and environmental safety;

- know-how protection in open value chains;

- assessment and management of uncertain and distributed risks;

- appropriate and fair conduct in the event of a conflict of objectives, binding domain and quality models, rules, and policies (e.g., compliance)

\section{Sustainable Innovation and the Expected Social Effects}

Intelligent infrastructures develop in a changing context, and they themselves change the structure of the social system. Digital communications allow people to obtain information more rapidly. Due to their significant transformational potential, new socio-technical systems command increased attention from civil society and its institutions. Realtime access to information and the ability to actively respond to it against the background of growing network density and the related cascading effects, contribute to the emergence of new, "liquid" forms of democracy [Blum, Zuber, 2016]. Better-quality and more timely information encourages citizens become more involved in the decision-making process regarding the implementation of socio-technical systems. Thus, technology becomes important not only for professionals, but also for all of society. Greater participation by civil society responds to the demand for participatory democracy. Therefore, new technical solutions must have ecological, economic, and social dimensions. We are talking about sustainable innovation [Schot, Geels, 2008; Boons, Lüdeke-Freund, 2013]. However, greater participation alone will not be enough. Sociotechnical projects must remain realistic so as not to endanger the territories where they take place. Also, sustainable innovation must be robust [Roth, 2015]. Socio-technical systems require sustainable information infrastructure as a prerequisite for

${ }^{4}$ For more see: https://uits.iu.edu/ii, accessed on 26.09.2020. 
building up society's innovative potential. There is a growing need to create integrated research and education centers specializing in engineering and natural sciences, humanities, and social sciences [van Kerkhoff, 2014]. New university formats are emerging in these interdisciplinary research clusters. They leave behind the traditional distinction between the aforementioned scientific domains. They can be viewed as matrix structures, where disciplines are matrix lines, while matrix columns are complex research projects covering various elements of disciplines depending upon the objectives of the study. Such projects are not just a promis ing idea, they are already being implemented by universities on the basis of their experience. The author of this paper was directly involved in the creation of competence centers at the technical universities of Augsburg and Munich. ${ }^{5}$

All these approaches are based on the fundamental idea that science does not exist independently of society. Without taking into account social structures and processes, any technological or natural science-related innovations (especially in the AI field) are unlikely to become successful. For example, building a smart city requires an understanding of how to organize the effective coexistence of people and smart infrastructure. Smart supply chains designed to meet the needs of the world's growing population will not work without considering the context of developing countries. Robots will not be effective assistants for older people if there is no understanding of the latter's true needs. Ignoring the relevant social, economic, and environmental factors will prevent the harmonious integration of large-scale technology projects into the social structure.

\section{Conclusions}

Information and communication technologies are transforming most industries. According to the previously dominant belief, their development follows exponential laws, so to achieve economic success, it is enough to flexibly adapt to this logic. In reality though, technological development has never been subject to rigid laws. It is still not possible to accurately determine which promising development ideas may emerge in the future. Like all live systems, scientific and technological progress develops in dynamic complexity, but unlike biological evolution, it can be controlled by people who are able to influence its vector. This requires interdisciplinary thinking and an understanding of how production and educational strategies should be organized in the concept of complex, dynamic systems. Research results will only be practical if the objectives are set taking into account social sciences and humanities, choosing relevant criteria, going beyond the established notions, and learning from crises.

What would development strategies that take into account complex dynamic systems look like? Interdisciplinary issues should be addressed from the very start of any project, not during the subsequent "review".

Any scientific and technological project must involve researchers from the humanities: to study related social aspects, evaluate the results for compliance with economic, medical, environmental, and technological ethics, and develop new mechanisms for exchanging ideas between science and society. Empirical research should be interdisciplinary and project-oriented, while research results should be open for public discussion to serve as the basis for policy decisions.

In an increasingly informed society, the potential for people's involvement in decision-making on infrastructure and technology-related issues increases. Trying to regulate this process, countries develop clear step-by-step approval procedures: the project developer prepares a plan, next come consultations, a public presentation, a discussion, the presentation of its results, and the approval of the plan. However, public participation is often organized in the form of hearings, with project implementation remaining under the exclusive control of the authorities. The so-called "preclusion effect" [Ketchum, 2016] makes any appeals after a certain period of time impossible. While objective technical, social and economic conditions may change, this approach leaves no room for adaptive learning and adjustment. Such a "linear" legitimization procedure needs to be revised taking into account the ongoing global transformations. Boundaries for the application of a participatory approach must be established, to preserve the effectiveness of decisionmaking systems and maintain the social balance. Political structures are changing under the influence of technological and economic development and the emergence of new environmental trends. It is necessary to rethink the rules of the game to make coordinated, collective decisions in the context of a dialogue between all branches of government with the academic and business communities and the general public. For the future generations

In 2012, as founding director of the Munich Center for Technology in Society (MCTS) at the Technical University of Munich as part of the Excellence Initiative 2012, and before that (in 1998) as founding director and the first head of the Institute for Interdisciplinary Computer Science of the University of Augsburg to analyze the societal impact of the internet. 
of engineers, ICT professionals, and scientists, contact with the public will become an integral aspect of their work; therefore the skills required for such communication must be learned from the very beginning of their professional education. Taking into account the human factor should be seen as an important aspect of the technological design of human-machine interactions in the development of artificial intelligence. The big questions for the future of artificial intelligence can only be answered by interdisciplinary studies. Each project step should be examined at both the technical and the organizational level over the course of a dialogue with society, to cover and take into account all kinds of social consequences and challenges, and to see unexpected promising directions.

\section{References}

Acatech (2011) Cyber-Physical Systems. Driving force for innovation in mobility, health, energy and production, Berlin: National Academy of Science and Engineering (ACATECH). Available at: https://www.acatech.de/publikation/cyber-physicalsystems/download-pdf?lang=wildcard, accessed 15.09.2020.

Acatech (2012) Technology Futures. Anticipation - Creation - Assessment (English Summary), Berlin: National Academy of Science and Engineering (ACATECH).

Al Dakheel J., Del Pero C., Aste N., Leonforte F. (2020) Smart buildings features and key performance indicators: A review. Sustainable Cities and Society, vol. 61, art. 102328. Available at: https://doi.org/10.1016/j.scs.2020.102328, accessed 19.09.2020.

Alegre H., Vitorino D., Coelho S. (2014) Infrastructure value index: A powerful modelling tool for combined long-term planning of linear and vertical assets. Procedia Engineering, vol.89, pp. 1428-1436. Available at: https://doi.org/10.1016/j. proeng.2014.11.469, accessed 06.08.2020.

Bansraj D.S., Smit H.T.J., Volosovych V. (2018) Can Private Equity Act as Strategic Buyers? Evidence from Serial (Buy-andBuild) Strategies? Paper presented at the 2019 FMA European Conference, 12-14 June 2019, Glasgow, Scotland. Available at: http://www.fmaconferences.org/Glasgow/Papers/Buy_and_Build_FMAEur_2019.pdf, accessed 04.07.2020.

Bassett M., Wilkinson S., Mannakkara S. (2017) Legislation for building back better of horizontal infrastructure. Disaster Prevention and Management, vol. 26, no 1, pp. 94-104. DOI: 10.1108/DPM-03-2016-0054.

Behymer K.J. Flach J.M. (2016) From Autonomous Systems to Sociotechnical Systems: Designing Effective Collaborations. She Ji: The Journal of Design, Economics, and Innovation, vol. 2, no 2, pp. 105-114.

Berg M. (1998) The politics of technology: On bringing social theory into technological design. Science Technology and Human Values, vol. 23, no 4, pp. 456-490. DOI: 10.1177/016224399802300406.

Bezemek C. (2019) The 'Normative Force of the Factual': A Positivist's Panegyric. The Normative Force of the Factual. Legal Philosophy Between Is and Ought (eds. N. Bersier-Ladavac, C. Bezemek, F. Schauer), Heidelberg, New York, Dordrecht, London: Springer, pp. 65-77.

Biggs M. (2017) Self-fulfilling prophecies. The Oxford Handbook of Analytical Sociology (eds. P. Bearman, P. Hedström), Oxford: Oxford University Press, pp. 294-314 DOI: 10.1093/oxfordhb/9780199215362.013.13.

Blum C., Zuber C.I. (2016) Liquid democracy: Potentials, problems, and perspectives. Journal of Political Philosophy, vol. 24, no 2, pp. 162-182. Available at: https://doi.org/10.1111/jopp.12065, accessed 07.04.2020.

Boons F., Ludeke-Freund F. (2013) Business models for sustainable innovation: State-of-the-art and steps towards a research agenda. Journal of Cleaner Production, vol. 45, pp. 9-19. Available at: https://doi.org/10.1016/j.jclepro.2012.07.007, accessed 07.04.2020.

Boy G.A. (ed.) (2017) The handbook of human-machine interaction: A human-centered design approach, Burlington, VT: Ashgate Publishing.

Dean J. (2014) Big data, data mining, and machine learning. Value creation for business leaders and practitioneers, Hoboken, NJ: Wiley.

European Commission (2006) European Technology Platform SmartGrids. Vision and Strategy for Europe's Electricity Networks of the Future, Brussels: European Commission. Available at: http://ec.europa.eu/research/energy/pdf/smartgrids_en.pdf, accessed 30.07.2020. 
Geisberger E., Broy M. (eds.) (2012) Living in a Networked World. Integrated Research Agenda on Cyber-Physical Systems (agendaCPS), Berlin: National Academy of Science and Engineering (ACATECH). Available at: https://www.acatech. de/publikation/agendacps-integrierte-forschungsagenda-cyber-physical-systems/download-pdf?lang=en, accessed 19.09.2020

Giaimo F., Andrade H., Berger C. (2020) Continuous experimentation and the cyber-physical systems challenge: An overview of the literature and the industrial perspective. Journal of Systems and Software, vol. 170, art. 110781. Available at: https://doi. org/10.1016/j.jss.2020.110781, accessed 27.08.2020.

Glenn J.C., Gordon T.J. (eds.) (2009) Futures research methodology - Version 3.0 (CD-ROM).Washington, D.C.: The Millennium Project. Available at: http://www.millennium-project.org/millennium/FRM-V3.html\#toc, accessed 22.11.2019.

Godet M., Roubelat F. (1996) Creating the Future: The Use and Misuse of Scenarios. Long Range Planning, vol. 29, no 2, pp. 164-171. Available at: https://doi.org/10.1016/0024-6301(96)00004-0, accessed 22.08.2020.

Häder M. (ed.) (2002) Delphi Interviews. A Workbook, Heidelberg, New York, Dordrecht, London: Springer.

Hawkins W., Abdelzaher T. (2005) Towards feasible region calculus: An end-to-end schedulability analyzis of real-time multistage execution. Proceedings of the 26th IEEE International Real-Time Systems Symposium (RTSS '05), Washington, D.C.: IEEE Computer Society, pp. 75-86. Available at: https://doi.org/10.1109/RTSS.2005.42, accessed 19.09.2020.

Isermann R. (2009) Mechatronic Systems - A Short Introduction. Springer Handbook of Automation (ed. S.Y. Nof), Heidelberg, New York, Dordrecht, London: Springer, pp. 317-331.

Jones A.J.I., Artikis A., Pitt J. (2011) The design of intelligent socio-technical systems. Artificial Intelligence Review, vol. 39, no 1, pp. 5-20. DOI: 10.1007/s10462-012-9387-2.

Ketchum B.J. (2016) Keeping tabs: When Will TTAB Decisions Have Preclusive Effect? Preclusive Effect of T.T.A.B. Likelihood of Confusion Decisions after B \& B v. Hargis Industries. Journal of Intellectual Property, vol. 15, no 1, pp. $141-161$.

King A.S. (1973) Self-Fulfilling Prophecies in Organizational Change. Social Science Quarterly, vol. 54, no 2, pp. $384-393$.

Lee E.A., Seshia S.A. (2016) Introduction to embedded systems: A cyber-physical systems approach, Cambridge, MA: MIT Press.

Lozito G.M., Salvini A. (2020) Swarm intelligence based approach for efficient training of regressive neural networks. Neural Computing and Applications, vol. 32, no 14, pp. 10693-10704. DOI: 10.1007/s00521-019-04606-X.

Mainzer K. (2007) Thinking in Complexity. Computational Dynamics of Matter, Mind, and Mankind (5 ${ }^{\text {th }}$ ed.), Heidelberg, New York, Dordrecht, London: Springer.

Mainzer K. (2019) Artificial Intelligence. When do Machines Take Over?, Heidelberg, New York, Dordrecht, London: Springer.

Nelson R. (2018) Modern Evolutionary Economics - An Overview, Cambridge, MA: Cambridge University Press.

Nelson R., Winter S.G. (1982) An Evolutionary Theory of Economic Change, Cambridge, MA: Harvard University Press.

NSF (2008) Cyber-Physical Systems. Program Announcements \& Information, Arlington, VA: National Science Foundation.

Pop O.-M. (2015) Self-Fulfilling Prophecies and Innovation Success. Available at: https://blog.hypeinnovation.com/selffulfilling-prophecies-and-innovation-success, accessed 28.09.2020.

Rajkumar R., Lee I., Sha L., Stankovic J. (2010) Cyber-physical systems: The next computing revolution- Design automation. Proceedings of the Design Automation Conference, Piscataway, NJ: IEEE, pp. 731-737. DOI: 10.1145/1837274.1837461.

Ringland G. (2010) The role of scenarios in strategic foresight. Technological Forecasting and Social Change, vol. 77, no 9, pp. 1493-1498. DOI:10.1016/j.techfore.2010.06.010.

Roth S.(ed.) (2015) Non-technological and non-economic innovations: Contributions to a theory of robust innovation, Kiel (Germany): ZBW - Leibniz Information Centre for Economics.

Sa I., Corke P. (2014) Vertical infrastructure inspection using a quadcopter and shared autonomy control. Field and Service Robotics: Results of the 8th International Conference (Series: Springer Tracts in Advanced Robotics, vol. 92) (eds. K. Yoshida, S. Tadokoro), Heidelberg, New York, Dordrecht, London: Springer, pp. 219-232.

Schiff J.L. (2007) Cellular Automata: A Discrete View of the World, New Tork: John Wiley \& Sons.

Schot J., Geels F.W. (2008) Strategic niche management and sustainable innovation journeys: Theory, findings, research agenda, and policy. Technology Analyzis and Strategic Management, vol. 20, no 5, pp. 537-554. Available at: https://doi. org/10.1080/09537320802292651, accessed 15.08.2020. 
Tantawi K.H., Sokolov A., Tantawi O. (2019) Advances in Industrial Robotics: From Industry 3.0 Automation to Industry 4.0 Collaboration. Proceedings of the 4th Technology Innovation Management and Engineering Science International Conference (TIMES-iCON 2019), art. 9024658. Available at: https://ieeexplore.ieee.org/document/9024658, accessed 30.05.2020.

van de Poel I. (2020) Embedding Values in Artificial Intelligence (AI) Systems. Minds and Machines (in press, first published online 01.09.2020). Available at: https://link.springer.com/article/10.1007/s11023-020-09537-4, accessed 14.08.2020.

van der Heijden K. (1996) Scenarios: The Art of Strategic Conversation, New York: Wiley \& Sons.

van Kerkhoff L. (2014) Developing integrative research for sustainability science through a complexity principles-based approach. Sustainability Science, vol. 9, pp. 143-155.

Wayne W. (2008) Computers as Components: Principles of Embedded Computing Systems Design, Amsterdam: Morgan Kaufmann.

Wedde H.E., Lehnhoff S., van Bonn B., Bay Z., Becker S., Böttcher S., Brunner C., Büscher A., Fürst T., Lazarescu A.M., Rotaru E., Senge S., Steinbach B., Yilmaz F., Zimmermann T. (2007) Highly dynamic and adaptive traffic congestion avoidance in real-time inspired by honey bee behavior. Mobilität und Echtzeit (eds. P. Holleczek, B. Vogel-Heuser), Heidelberg, New York, Dordrecht, London: Springer, pp. 21-31. DOI: 10.1007/978-3-540-74837-3_3. 